\title{
Vínculos de trabalho no setor saúde: o cenário da precarização na macrorregião Oeste do Paraná
}

\author{
Employment bonds in the health sector: the precariousness scenery at \\ the Western macro-region of Paraná (BR)
}

Leonardo Dresch Eberhardt', Manoela de Carvalho², Neide Tiemi Murofuse ${ }^{\mathbf{3}}$

RESUMO Com o objetivo de identificar, na macrorregião oeste do estado do Paraná, os trabalhadores da saúde submetidos a vínculos de trabalho precários, foi realizado um estudo quantitativo, com análise estatística descritiva simples, utilizando dados do Cadastro Nacional de Estabelecimentos de Saúde, coletados em março de 2014. Identificou-se a presença de 10.330 vínculos precários, que representam $36,46 \%$ do universo da pesquisa. A situação da precarização dos vínculos trabalhistas esteve mais presente entre os profissionais de nível superior que desempenham atividades nucleares. Observou-se a necessidade de aprofundar estudos a respeito de todas as dimensões do trabalho precário em saúde.

PALAVRAS-CHAVE Força de trabalho; Recursos humanos em saúde; Emprego; Relações trabalhistas; Gestão em saúde.

ABSTRACT With the aim of identifying, at the western macro-region of Parana, the health workers submitted to precarious employment bonds, it was carried out a quantitative study, with simple descriptive statistical analysis, by using data from the National Registration of Health Establishments, collected on March, 2014. It was identified the presence of 10.330 precarious bonds, which represent $36,46 \%$ of the research universe. The situation of precariousness of the employment bonds was mostly present among the higher education professionals that develop nuclear activities. It was observed the necessity to deepen studies about every dimension of precarious working in health.

KEYWORDS Labor force; Human resources in health; Employment; Labor relations; Health management.

\footnotetext{
1 Universidade Estadual do Oeste do Paraná (Unioeste)Cascavel (PR), Brasil. leonardodeberhardt@ gmail.com

2 Universidade Estadual do Oeste do Paraná (Unioeste) - Cascavel (PR), Brasil. manoela.carvalho@unioeste.br 


\section{Introdução}

O problema da precarização do trabalho vem se constituindo como preocupação de diversos campos do conhecimento, com destaque para a sociologia do trabalho, a gestão do trabalho e a saúde do trabalhador. Inúmeros estudos têm sido publicados a respeito dessa temática, especialmente nas duas últimas décadas (ANTUNES, 1995; KOSTER, 2008; KALLEBERG, 2009; SILVEIRA ET AL., 2010; FARIA; DALBELLO-ARAUJO, 2011).

Além de preocupar pesquisadores, a precarização do trabalho vem ocupando lugar especial na agenda de ações de diversos atores sociais e órgãos governamentais nacionais e internacionais, como o Ministério da Saúde brasileiro, por meio da Secretaria de Gestão do Trabalho e da Educação em Saúde (SGTES), o Conselho Nacional de Secretarias Municipais de Saúde(Conasems), o Conselho Nacional de Secretários de Saúde (Conass) e a Organização Internacional do Trabalho (OIT), entre outros ministérios e secretarias voltados às questões relacionadas à saúde (KALLEBERG, 2009; BRASIL, 2006A; 2011). A questão da precarização do trabalho no setor saúde tem sido apontada como um desafio para a gestão do trabalho no Sistema Único de Saúde (SUS) (BRASIL, 2006A).

Definir o conceito de precarização do trabalho é uma tarefa complexa. Kalleberg (2009) define 'trabalho precário' como o trabalho incerto e imprevisível, no qual os riscos empregatícios são assumidos principalmente pelos trabalhadores e não pelos seus empregadores ou pelo governo. Borsoi (2011), por sua vez, considera a precarização do trabalho, atualmente, como um resultado da flexibilização de direitos trabalhistas historicamente conquistados pela classe trabalhadora. Antunes (1995) aponta que a precarização do trabalho vivenciada contemporaneamente é um dos resultados da reestruturação produtiva do capital operada a partir da década de 1970, caracterizada pela passagem da organização taylorista-fordista da produção para uma organização toyotista, que estimula a adoção de vínculos de trabalho mais flexíveis, do ponto de vista do empregador, e mais precários, do ponto de vista do trabalhador.

O Ministério da Saúde define trabalho precário como aquele realizado sem a proteção social do trabalhador e, na administração pública, engloba também todo trabalho realizado sem concurso público (BRASIL, 2009). O Conasems e o Conass consideram como precário o trabalho realizado sem garantia de direitos sociais para os trabalhadores, porém defendem a flexibilização do trabalho em certos casos (KOSTER, 2008).

No setor saúde, vários autores (KOSTER, 2008; ANDRADE, 2009; GARCIA, 2010; ENTRE OUTROS) têm apontado que a precarização do trabalho se intensificou em decorrência da Reforma do Estado operada no Brasil, na década de 1990, que objetivava 'reduzir o papel do Estado' e seu 'tamanho'. Tal operação teve como fundamento teórico-político o ideário neoliberal, cujo arcabouço teórico foi elaborado por Hayek, Friedman, Popper e outros, entre as décadas de 1940 e 1960 (ANDERSON, 2003). Esse arcabouço restaura o mercado como instância mediadora societal elementar e insuperável, e propõe o Estado mínimo ${ }^{\boldsymbol{1}}$ como única alternativa e forma para a democracia. Tais ideias eram, em sua essência, uma resposta ao Estado de Bem-Estar Social (Welfare State) construído na Europa, no segundo pós-guerra (PAULO NETTO, 1993).

Esse ideário passou a ganhar força após a crise do Estado de Bem-Estar (ou a crise do padrão de acumulação fordista-keynesiano), no início da década de 1970 (MONTAÑo; DURIGUETTO, 2011). O controle e a organização do trabalho baseados nos pressupostos tayloristas-fordistas impuseram limites para a expansão do capital, havendo a necessidade de reorganização das relações trabalhistas segundo os preceitos de desregulamentação e flexibilização de tais vínculos sugeridos pelo modelo toyotista de gestão do trabalho.

\footnotetext{
1 Paulo Netto (1993) explica que a pretensão do ideário neoliberal não é a 'redução da intervenção do Estado', mas sim direcionar essas intervencões para os interesses da classe burguesa. Tratase, portanto, de um 'Estado mínimo' para os trabalhadores e, ao mesmo tempo, de um 'Estado máximo' para o capital.
} 
O trabalho passa a ser desregulamentado e flexibilizado para dotar o capital de ferramentas necessárias a sua adaptação às crises. Este movimento acaba por afetar direitos trabalhistas e tornar as relações transitórias. Também não se limitou a um só ramo produtivo, afetando também serviços públicos, como os do SUS, minando a potência desta nossa política social. (FARIA; DALBELLO-ARAÚJO, 2011, P. 145).

No setor saúde, a questão da precarização do trabalho tem sido apontada como um desafio para a gestão do trabalho no SUS. Nessa perspectiva, considerando a importância do tema e com a finalidade de conhecer o cenário de precarização do trabalho em saúde na macrorregião oeste do Paraná, este estudo se propõe a: 1 . Descrever, quantitativamente, 'quem' ocupa os vínculos precários do setor saúde nessa macrorregião, quanto à formação profissional, ao nível de formação e ao tipo de atividade que desempenha; e 2. Identificar a distribuição dos vínculos precários de trabalho conforme o município, a esfera administrativa e a classificação por serviço de atenção. Atingindo tais objetivos, espera-se contribuir para o planejamento de ações que visem à proteção social dos trabalhadores em condições precárias.

\section{Procedimentos metodológicos}

Trata-se de um estudo descritivo vinculado ao projeto de pesquisa 'Força de trabalho em saúde: estrutura, dinâmica e tendência na macrorregião oeste do Paraná', financiado pela Fundação Araucária (Chamada Pública 04/2012 - Programa de pesquisa para o Sistema Único de Saúde: Gestão compartilhada em saúde PPSUS - Edição 2011. Processo $n^{\circ}$ 35038), que tem como objetivo central caracterizar o perfil da força de trabalho em saúde na macrorregião oeste do Paraná quanto à oferta, à composição, à distribuição e aos vínculos de trabalho. Por utilizar dados públicos, não foi necessária a apreciação pelo Comitê de Ética em Pesquisa. Foram garantidos o sigilo e o anonimato dos envolvidos.

A primeira fase da pesquisa constituiu-se em uma revisão bibliográfica a respeito da gestão do trabalho no SUS, realizada no decorrer de 2013, utilizando textos publicados até este mesmo ano. A busca dos textos foi realizada na Biblioteca Virtual em Saúde², utilizando as palavras-chave 'gestão do trabalho' e 'precarização', no título e em método integrado. Foram selecionadas publicações com texto completo e que tratavam especificamente do trabalho na área da saúde.

A segunda fase consistiu na coleta de dados da macrorregião oeste do Paraná. O Plano Diretor de Regionalização do Paraná, instrumento de ordenamento da hierarquização e da regionalização da assistência à saúde no Estado, propõe a definição de seis macrorregiões, com o objetivo de articular os atores e somar esforços para a solução de problemas comuns. Atualmente, a macrorregião oeste é composta por cinco regionais, devido a uma redistribuição das regionais de saúde, ocorrida após o início do presente estudo. No entanto, no presente estudo, para a análise da macrorregião oeste, foram consideradas quatro regionais de saúde $\left(8^{\mathrm{a}}, 9^{\mathrm{a}}, 10^{\mathrm{a}}\right.$ e $20^{\mathrm{a}}$ ), totalizando 79 municípios e uma população de 1.647.657 habitantes (PARANÁ, 2009).

Os dados a respeito da força de trabalho em atuação nos serviços de saúde da macrorregião oeste foram coletados no Cadastro Nacional de Estabelecimento de Saúde (CNES), em março de 2014. Segundo o próprio site do CNES (BRASIL, 2014), o cadastro visa disponibilizar informações das atuais condições de infraestrutura e de funcionamento dos estabelecimentos de saúde em todas as esferas. O cadastro abrange a totalidade dos estabelecimentos de saúde existentes no País, sejam eles prestadores de serviços de saúde ao Sistema Único de Saúde (SUS) ou não (BRASIL, 2006B). 
O universo da pesquisa contemplou 28.329 vínculos de trabalho, distribuídos em diversos estabelecimentos de saúde. Para este estudo, foram selecionados os 10.330 vínculos classificados como precários. Para a organização e a sistematização das informações coletadas por meio da consulta ao CNES, foi construído um banco de dados utilizando o software Microsoft Excel. Este software também foi utilizado para a realização da análise dos dados, que se constituiu em uma análise estatística descritiva simples.

Os dados coletados foram classificados em seis grupos: a) tipos de vínculos de trabalho; b) nível de formação dos trabalhadores; c) atividades desenvolvidas; d) tipo de serviços de saúde; e) tipo de esfera administrativa; e f) porte dos municípios. No primeiro grupo referente aos vínculos de trabalho, o agrupamento foi feito de três maneiras: protegidos, precários ou sem informação. No grupo dos protegidos foram incluídos os seguintes vínculos: celetista, emprego público e estatutário. Foram considerados como vínculos precários: autonomia; bolsa; cargo comissionado; consultoria; contrato por prazo determinado; contrato verbal/informal; cooperativa; estágio; e residência. Na categoria 'autônomo' foram contemplados tanto os vínculos diretos, sem intermediação, quanto os intermediados por diferentes entidades, tais como: organização da sociedade civil de interesse público; entidade filantrópica e/ ou sem fins lucrativos; cooperativa; empresa privada; empresa não governamental; e organização social. E foram classificados como 'sem informação' quando o tipo de vínculo não constava do CNES.

A segunda classificação foi quanto ao nível de formação dos trabalhadores: a) profissionais de saúde com formação de nível superior (médico, enfermeiro, dentista, assistente social etc.); b) profissionais e trabalhadores de saúde sem formação de nível superior (agente comunitário de saúde, atendente de farmácia, auxiliar de enfermagem, auxiliar de saúde bucal, técnico de enfermagem etc.); c) outros trabalhadores de nível superior sem formação na área de saúde (administrador, engenheiro, advogado etc.); e d) outros trabalhadores sem identificação da formação (costureiro, cozinheiro, digitador, gerente etc.).

Para o agrupamento das atividades desenvolvidas pelos trabalhadores, utilizou-se a metodologia proposta por Dedecca et al. (2005), sendo elas segmentadas em: nucleares; afins; apoio/manutenção; e sem informação, conforme sua relação mais ou menos direta com as atividades de atenção à saúde. Quanto aos serviços de atenção à saúde, estes foram classificados em: Atenção Básica (AB); atenção hospitalar; atenção intermediária; e serviços administrativos. E ainda houve a classificação dos serviços de saúde de acordo com a esfera administrativa: federal; estadual; municipal; e privada. Por fim, para a classificação dos portes dos municípios, tomou-se como referência a população residente nos mesmos, segmentadas em: a) menos de 5 mil habitantes; b) entre 5 mil e 20 mil habitantes; c) entre 20 mil e 50 mil habitantes; d) entre 50 mil e 100 mil habitantes; e e) mais de 100 mil habitantes.

\section{Resultados e discussões}

Do universo composto por 28.329 vínculos de trabalho, distribuídos em diversos estabelecimentos de saúde das quatro regionais de saúde $\left(8^{\mathrm{a}}, 9^{\mathrm{a}}, 10^{\mathrm{a}}\right.$ e $\left.20^{\mathrm{a}}\right)$, obteve-se um total de 10.330 vínculos classificados como precários, correspondentes a $36,46 \%$ das modalidades de vinculação dos trabalhadores da saúde na macrorregião oeste do Paraná. Foram constatadas nove diferentes formas de integração dos trabalhadores da saúde ao mercado de trabalho, nessa região, sendo a grande maioria $(75,99 \%)$ constituída pela vinculação 'autônoma', e parcela significativa $(18,83 \%)$ representada pelos 'contrato por prazo determinado' (tabela 1). 


\begin{tabular}{|c|c|c|c|c|c|c|c|c|c|c|}
\hline \multirow{3}{*}{ Tipos de vínculos } & \multicolumn{10}{|c|}{ Nível de formação } \\
\hline & \multicolumn{2}{|c|}{ A } & \multicolumn{2}{|c|}{ B } & \multicolumn{2}{|c|}{ C } & \multicolumn{2}{|c|}{ D } & \multicolumn{2}{|c|}{ Total } \\
\hline & $\mathbf{N}$ & $\%$ & $\mathbf{N}$ & $\%$ & $\mathbf{N}$ & $\%$ & $\mathbf{N}$ & $\%$ & $\mathbf{N}$ & $\%$ \\
\hline Autônomo & 7.251 & 70,19 & 409 & 3,96 & 74 & 0,72 & 116 & 1,12 & 7.850 & 75,99 \\
\hline Bolsa & 40 & 0,39 & - & - & - & - & - & - & 40 & 0,39 \\
\hline Cargo comissionado & 75 & 0,73 & 61 & 0,59 & 49 & 0,47 & 82 & 0,79 & 267 & 2,58 \\
\hline Consultoria & 12 & 0,12 & - & - & 1 & 0,01 & - & - & 13 & 0,13 \\
\hline $\begin{array}{l}\text { Contrato por prazo } \\
\text { determinado }\end{array}$ & 1.293 & 12,52 & 497 & 4,81 & 36 & 0,35 & 119 & 1,15 & 1.945 & 18,83 \\
\hline $\begin{array}{l}\text { Contrato } \\
\text { verbal/informal }\end{array}$ & 54 & 0,52 & 11 & 0,11 & 11 & 0,11 & 15 & 0,15 & 91 & 0,88 \\
\hline Cooperativa & 25 & 0,24 & - & - & 1 & 0,01 & - & - & 26 & 0,25 \\
\hline Estágio & 6 & 0,06 & 20 & 0,19 & - & - & 19 & 0,18 & 45 & 0,44 \\
\hline Residência & 53 & 0,51 & - & - & - & - & - & - & 53 & 0,51 \\
\hline Total & 8.809 & 85,28 & 998 & 9,66 & 172 & 1,67 & 351 & 3,40 & 10.330 & 100 \\
\hline
\end{tabular}

Fonte: BRASIL, 2014

Legenda: A - Profissionais de saúde com formação de nível superior; B - Profissionais e trabalhadores de saúde sem formação de nível superior; C - Outros trabalhadores de nível superior sem formação na área de saúde; D - Outros trabalhadores sem identificação da formação

A análise da distribuição dos vínculos precários de acordo com o nível de formação dos trabalhadores constatou que a maioria (85,28\%) concentrava-se entre os profissionais de saúde com formação de nível superior (A), estando a maior parte na modalidade 'autônomo' (70,19\%), seguida pela modalidade 'contrato por prazo determinado' (12,52\%) (tabela 1). A situação de precariedade desse grupo de profissionais continua, ainda que se considere o número total de profissionais de saúde com nível superior do universo do estudo ( $\mathrm{N}=14.846)$, representando 59,34\% dos vínculos estabelecidos com esses profissionais.

Situação parecida é vivenciada pelos demais trabalhadores de nível superior sem formação na área da saúde (C). Os vínculos precários entre esses profissionais representam apenas 1,67\% de todos os deste tipo. Entretanto, se resgatada a relação existente entre os vínculos precários e o total de vínculos estabelecidos com esses profissionais $(\mathrm{N}=391)$, percebe-se que 43,99\% deles são precários. Ou seja, a situação dos profissionais com formação de nível superior é a mais precária.
A situação dos profissionais e trabalhadores da saúde sem formação de nível superior (B) e a dos trabalhadores sem informação do nível de formação (D) parecem melhores: entre os primeiros, de um total de 10.063 vínculos, 9,92\% são precários; e entre os segundos, de um total de 3.029 vínculos, esse número sobre para $11,58 \%$.

Esses resultados indicam que a precarização dos vínculos de trabalho no setor de saúde, apesar das ações desenvolvidas pela Secretaria de Gestão do Trabalho e da Educação na Saúde (SGTES) do Ministério da Saúde para combatê-la, desde os meados dos anos de 2003, por meio do Programa Nacional de Desprecarização do Trabalho no SUS (DesprecarizaSUS) (BRASIL, 2006A), ainda persiste como um dos importantes problemas a serem equacionados no que se refere à força de trabalho, que afeta especialmente a organização da gestão dos serviços de saúde no âmbito do SUS. Dentre as propostas de intervenção do DesprecarizaSUS, destaca-se a necessidade de implementação de uma nova política como alternativa contraposta à administração de recursos humanos, em que 
o trabalhador, como sujeito fundamental do processo de trabalho em saúde e mediador do direito à saúde, seja percebido como um sujeito transformador e protagonista das práticas e políticas, e não como um mero recurso realizador de tarefas previamente estabelecidas pela gerência (BRASIL, 2009; AGUIAR FILHO, 2012).

No entanto, Nogueira (2006) ressalta que, na expressão 'desprecarização do trabalho', não está implícita a ideia de beneficiar o trabalhador com reparação de seus direitos ou da sua manutenção na função que vem exercendo. Ao contrário, entende-se que os já 'precarizados' deverão, mais cedo ou mais tarde, deixar suas funções, sendo substituídos por outros trabalhadores ingressantes na administração pública mediante concurso.

Dedecca e Trovão (2013) indicam que, nas últimas décadas, observam-se esforços crescentes na produção de estudos sobre o trabalho no complexo da saúde no Brasil, especialmente a partir da Constituição Federal de 1988. A partir desse momento, em que se estabeleceu o direito universal de acesso aos serviços de saúde, a ampliação da cobertura e dos gastos com políticas públicas exigiu maiores investimentos no quantitativo de pessoal que atua nos serviços de saúde, além de ter impulsionado o crescimento de todo o complexo industrial da saúde, onde também há necessidade de investigações acerca do trabalho desenvolvido. Ressaltam, ainda, que a questão do trabalho é uma das dimensões relevantes do complexo da saúde no Brasil, nos últimos 20 anos, especialmente, pela expansão dos serviços de atendimento à saúde e das suas especificidades, que têm representado significativo peso em termos de geração de novas oportunidades ocupacionais. A tendência de crescimento do emprego decorrente da ampliação da cobertura da população à saúde e da diversificação dos serviços oferecidos, aliada ao envelhecimento populacional, em um cenário de restrição orçamentária, tem se manifestado na deterioração dos contratos e das relações de trabalho neste complexo (DEDECCA; TROVÃO, 2013).

Ao analisar os vínculos de trabalho precários do complexo da saúde do ponto de vista da ocupação na macrorregião estudada, verifica-se a presença da precariedade em todos os segmentos, sendo que a grande maioria (94,66\%) deles está entre os trabalhadores que desenvolvem atividades nucleares específicas da saúde (tabela 2).

Tabela 2. Distribuição dos tipos de vínculo precário segundo os tipos de atividade dos trabalhadores de saúde na macrorregião oeste do Paraná, 2014

\begin{tabular}{|c|c|c|c|c|c|c|c|c|c|c|}
\hline \multirow{3}{*}{ Tipos de vínculos } & \multicolumn{10}{|c|}{ Tipos de atividade } \\
\hline & \multicolumn{2}{|c|}{ Nucleares } & \multicolumn{2}{|c|}{ Afins } & \multicolumn{2}{|c|}{$\begin{array}{c}\text { Apoio e } \\
\text { manutenção }\end{array}$} & \multicolumn{2}{|c|}{$\begin{array}{c}\text { Sem informação } \\
\text { específica }\end{array}$} & \multicolumn{2}{|c|}{ Total } \\
\hline & $\mathbf{N}$ & $\%$ & $\mathbf{N}$ & $\%$ & $\mathbf{N}$ & $\%$ & $\mathbf{N}$ & $\%$ & $\mathbf{N}$ & $\%$ \\
\hline Autônomo & 7.661 & 74,16 & 174 & 1,68 & 14 & 0,14 & 1 & 0,01 & 7.850 & 75,99 \\
\hline Bolsa & 40 & 0,39 & - & - & - & - & - & - & 40 & 0,39 \\
\hline Cargo comissionado & 121 & 1,17 & 115 & 1,11 & 31 & 0,30 & - & - & 267 & 2,58 \\
\hline Consultoria & 12 & 0,12 & 1 & 0,01 & - & - & - & - & 13 & 0,13 \\
\hline Contrato por prazo determinado & 1.776 & 17,19 & 96 & 0,93 & 73 & 0,71 & - & - & 1.945 & 18,83 \\
\hline Contrato verbal/informal & 65 & 0,63 & 18 & 0,17 & 8 & 0,08 & - & - & 91 & 0,88 \\
\hline Cooperativa & 25 & 0,24 & 1 & 0,01 & - & - & - & - & 26 & 0,25 \\
\hline Estágio & 25 & 0,24 & 5 & 0,05 & 15 & 0,15 & - & - & 45 & 0,44 \\
\hline Residência & 53 & 0,51 & - & - & - & - & - & - & 53 & 0,5 \\
\hline Total & 9.778 & 94,66 & 410 & 3,97 & 141 & 1,36 & 1 & 0,01 & 10.330 & 100 \\
\hline
\end{tabular}

Fonte: BRASIL, 2014 
Nas atividades nucleares, analisou-se o percentual de vínculos precários, por categoria profissional, observando-se que entre os médicos, $78,88 \%$ dos vínculos de trabalho eram precários, sendo a maior parte deles contratados como 'autônomos', o que representa $86 \%$ de todos os vínculos entre profissionais médicos. Outras categorias, nas atividades nucleares, que apresentaram altos percentuais de precarização foram a dos fisioterapeutas (55,06\%), dos administradores (49,41\%), dos dentistas $(45,56 \%)$, dos fonoaudiólogos $(45,12 \%)$, dos nutricionistas $(40,83 \%)$, dos psicólogos (38,95\%), dos educadores físicos $(37,14 \%)$, dos técnicos em radiologia e imagenologia (34,77\%), dos farmacêuticos $(33,71 \%)$ e dos terapeutas ocupacionais (31,19\%). Em compensação, os auxiliares de serviços gerais (5,38\%) nas atividades de apoio e manutenção, os agentes comunitários de saúde (5,98\%) e os técnicos em enfermagem (7,38\%), nas atividades nucleares, apresentaram percentuais inferiores de precarização. Além de nestas categorias profissionais, a precarização esteve presente entre os ocupantes dos cargos de diretores de serviços de saúde, consideradas atividades afins $(80 \%$ dos vínculos de trabalho).

Na pesquisa coordenada por Carvalho e Girardi (2002), foram encontrados resultados semelhantes no que se refere à precarização do trabalho entre médicos e agentes comunitários de saúde que atuam em unidades básicas de saúde em que há a implantação do Programa Saúde da Família (PSF). Quanto aos primeiros, as formas precárias de vinculação atingiram cerca de $72 \%$ dos profissionais. Entre os agentes comunitários de saúde, no geral, observou-se maior grau de formalização nos vínculos de trabalho.

As atividades nucleares da saúde relacionam-se a atendimentos à saúde que incorporam riscos e que, diferentemente de outros setores, apresentam consequências que podem não ser passíveis de reversão. Assim, este campo de atuação encontra-se adequado a regulamentações públicas, geralmente relacionadas a profissões e ocupações com formação e qualificações específicas (DEDECCA; TROVÃO, 2013). Ainda de acordo com os mesmos autores, estas atividades possuem características particulares que organizam a estrutura ocupacional e deveriam estar menos expostas aos mecanismos de oferta e demanda da força de trabalho do mercado de trabalho em geral.

O trabalho em saúde é um ramo da prestação de serviços que compreende atividades essenciais para a vida humana. Com o desenvolvimento do capitalismo, a saúde sob a ótica do neoliberalismo é reuniversalizada através de uma vertente predominantemente economicista, traduzindo-se em ocupações marcadas por relações mercantis. A noção de mercado de trabalho, em economia, associa-se às relações estabelecidas entre indivíduos ou empresas na compra de força de trabalho (DEDECCA, 2008).

Para estabelecer políticas de gestão de trabalho que possam colocar o trabalhador como fundamental para o processo, respeitando os seus direitos trabalhistas e previdenciários, além de identificar 'quem' está vulnerável aos vínculos precários de trabalho, importante também é conhecer 'onde' esses vínculos estão distribuídos/concentrados. A distribuição dos vínculos de trabalho precários pelos tipos de serviços de atendimento do setor da saúde pode ser visualizada por meio da tabela 3 .

Neste estudo, identificou-se que a maioria dos vínculos precários (53,45\%) está localizada nos serviços hospitalares, e que $33,71 \%$ dos vínculos precários estão distribuídos nos serviços intermediários (tabela 3). Estes dois tipos de serviços, na macrorregião oeste do Paraná, concentram-se no setor privado. 
Tabela 3. Distribuição dos tipos de vínculo precários de acordo com os tipos de serviços de saúde na macrorregião oeste do Paraná, 2014

\begin{tabular}{|c|c|c|c|c|c|c|c|c|c|c|}
\hline \multirow{3}{*}{ Tipos de vínculos } & \multicolumn{10}{|c|}{ Tipos de serviços de saúde } \\
\hline & \multicolumn{2}{|c|}{ Atenção Básica } & \multicolumn{2}{|c|}{ Atenção Hospitalar } & \multicolumn{2}{|c|}{$\begin{array}{c}\text { Atenção } \\
\text { Intermediária }\end{array}$} & \multicolumn{2}{|c|}{ Administração } & \multicolumn{2}{|c|}{ Total } \\
\hline & $\mathbf{N}$ & $\%$ & $\mathbf{N}$ & $\%$ & $\mathbf{N}$ & $\%$ & $\mathbf{N}$ & $\%$ & $\mathbf{N}$ & $\%$ \\
\hline Autônomo & 230 & 2,23 & 4.881 & 47,25 & 2.730 & 26,43 & 9 & 0,09 & 7.850 & 75,99 \\
\hline Bolsa & 37 & 0,36 & 1 & 0,01 & 2 & 0,02 & - & - & 40 & 0,39 \\
\hline Cargo comissionado & 154 & 1,49 & 12 & 0,12 & 17 & 0,16 & 84 & 0,81 & 267 & 2,58 \\
\hline Consultoria & 2 & 0,02 & 2 & 0,02 & 8 & 0,08 & 1 & 0,01 & 13 & 0,13 \\
\hline $\begin{array}{l}\text { Contrato por prazo } \\
\text { determinado }\end{array}$ & 672 & 6,51 & 533 & 5,16 & 663 & 6,42 & 77 & 0,75 & 1.945 & 18,83 \\
\hline $\begin{array}{l}\text { Contrato } \\
\text { verbal/informal }\end{array}$ & 22 & 0,21 & 19 & 0,18 & 47 & 0,45 & 3 & 0,03 & 91 & 0,88 \\
\hline Cooperativa & 8 & 0,08 & 11 & 0,11 & 7 & 0,07 & - & - & 26 & 0,25 \\
\hline Estágio & 21 & 0,20 & 9 & 0,09 & 8 & 0,08 & 7 & 0,07 & 45 & 0,44 \\
\hline Residência & - & - & 53 & 0,51 & - & - & - & - & 53 & 0,5 \\
\hline Total & 1.146 & 11,09 & 5.521 & 53,45 & 3.482 & 33,71 & 181 & 1,75 & 10.330 & 100 \\
\hline
\end{tabular}

Fonte: BRASIL, 2014

Entre os vínculos precários de trabalho na Atenção Básica (11,09\%), a maioria se dá por meio dos contratos de prazo determinado (6,51\%). Estes índices obtidos no presente estudo são menores do que os encontrados no estudo de Silveira et al. (2010), realizado em 41 municípios das regiões Sul e Nordeste do Brasil, que revelaram que o vínculo precário de trabalho foi uma realidade para $38 \%$ dos trabalhadores da Atenção Básica. A maior prevalência de vínculo precário de trabalho foi encontrada entre os agentes comunitários de saúde (53\%) e o contrato temporário foi o tipo de vínculo precário de trabalho mais frequente (na região Sul, $49 \%$ dos contratos precários; e na região Nordeste, $67 \%$ ).

Uma das possíveis explicações para a diminuição da quantidade de vínculos precários na macrorregião oeste obtidos no presente estudo estaria na indicação feita por Koster (2008), de que alguns autores defendem a flexibilização do trabalho em certos casos como nos dos agentes comunitários de saúde e dos agentes de combate a endemias, que necessitam estar vinculados à região territorial de abrangência da Unidade Básica de Saúde (UBS) para desenvolverem seu trabalho adequadamente -, ainda que esta exigência não possa constar nos concursos públicos para o cargo, mas esses profissionais poderiam ser recrutados em processo seletivo público simples e contratados sob o regime da Consolidação das Leis do Trabalho (CLT). Desta maneira, sob a perspectiva de quem entende a precariedade apenas quando ocorre a admissão na instituição pública sem a realização de seleção sob a mesma natureza pública.

Entretanto, ainda permanecem sem respostas outros questionamentos: Como construir uma Atenção Básica resolutiva e (co)ordenadora do sistema de saúde com esse número de contratos precários por tempo determinado? Como se espera que o trabalhador crie e mantenha vínculos de confiança e de responsabilidade com os usuários? Como planejar e avaliar ações de médio e longo prazo, necessárias para estabelecer estratégias de promoção da saúde e prevenção de agravos, sabendo que brevemente não haverá mais vínculo com o serviço?

Quando se analisa a distribuição dos vínculos precários de acordo com a esfera administrativa da instituição de saúde na região estudada, verifica-se que a maioria (67,81\%) dos vínculos precários está localizada no setor privado, seguido pela esfera municipal (23,50\%) (tabela 4). 
Tabela 4. Distribuição dos tipos de vínculo precário segundo a esfera administrativa dos estabelecimentos de saúde na macrorregião oeste do Paraná, 2014

\begin{tabular}{|c|c|c|c|c|c|c|c|c|c|c|}
\hline \multirow{3}{*}{ Tipos de vínculos } & \multicolumn{10}{|c|}{ Esfera administrativa } \\
\hline & \multicolumn{2}{|c|}{ Federal } & \multicolumn{2}{|c|}{ Estadual } & \multicolumn{2}{|c|}{ Municipal } & \multicolumn{2}{|c|}{ Privada } & \multicolumn{2}{|c|}{ Total } \\
\hline & $\mathbf{N}$ & $\%$ & $\mathbf{N}$ & $\%$ & $\mathbf{N}$ & $\%$ & $\mathbf{N}$ & $\%$ & $\mathbf{N}$ & $\%$ \\
\hline Autônomo & - & - & 664 & 6,43 & 972 & 9,41 & 6.214 & 60,15 & 7.850 & 75,99 \\
\hline Bolsa & - & - & - & - & 37 & 0,36 & 3 & 0,03 & 40 & 0,39 \\
\hline Cargo comissionado & - & - & 13 & 0,13 & 254 & 2,46 & - & - & 267 & 2,58 \\
\hline Consultoria & - & - & - & - & 4 & 0,04 & 9 & 0,09 & 13 & 0,13 \\
\hline Contrato por prazo determinado & - & - & 174 & 1,68 & 1.081 & 10,46 & 690 & 6,68 & 1.945 & 18,83 \\
\hline Contrato verbal/informal & 1 & 0,01 & 3 & 0,03 & 28 & 0,27 & 59 & 0,57 & 91 & 0,88 \\
\hline Cooperativa & - & - & - & - & 10 & 0,10 & 16 & 0,15 & 26 & 0,25 \\
\hline Estágio & - & - & 1 & 0,01 & 33 & 0,32 & 11 & 0,11 & 45 & 0,44 \\
\hline Residência & - & - & 41 & 0,40 & 9 & 0,09 & 3 & 0,03 & 53 & 0,51 \\
\hline Total & 1 & 0,01 & 896 & 8,67 & 2.428 & 23,50 & 7.005 & 67,81 & 10.330 & 100 \\
\hline
\end{tabular}

Fonte: BRASIL, 2014

O significativo índice obtido em relação à esfera municipal pode ser explicado pela ocorrência da descentralização e da municipalização do SUS em um contexto bastante desfavorável, quando o Estado brasileiro submeteu-se a reformas neoliberais. Uma resultante dessas reformas foi a Lei de Responsabilidade Fiscal (LRF), que limita os gastos com força de trabalho em $60 \%$ da receita corrente líquida de estados e municípios (BRASIL, 2011). Essa restrição levou os municípios a buscarem outras formas de contração da força de trabalho, em geral precárias (SILVA; SILVA, 2007), como alternativa para a necessidade de expansão do SUS (ANDRADE, 2009).
A frequência dos tipos de vínculos precários segundo o porte dos municípios (tabela 5) revelou que cerca da metade $(55,15 \%)$ desses vínculos, na macrorregião oeste do Paraná, estava localizada nos municípios com população superior a 100 mil habitantes. Nessa macrorregião, existem apenas 3 municípios nessa condição: Cascavel (286.205 habitantes), Foz do Iguaçu (256.088 habitantes) e Toledo (119.313 habitantes). No conjunto dos municípios da região, municípios com menos de 5 mil habitantes (21 municípios) responderam por apenas $2,93 \%$ dos vínculos precários.

Tabela 5. Distribuição dos tipos de vínculo precário segundo o porte dos municípios da macrorregião oeste do Paraná, 2014

\begin{tabular}{|c|c|c|c|c|c|c|c|c|c|c|c|c|}
\hline \multirow{3}{*}{ Tipos de vínculos } & \multicolumn{12}{|c|}{ Porte dos municípios (número de habitantes) } \\
\hline & \multicolumn{2}{|c|}{ Menos de 5 mil } & \multicolumn{2}{|c|}{$\begin{array}{l}5 \text { mil até menos } \\
\text { de } 20 \mathrm{mil}\end{array}$} & \multicolumn{2}{|c|}{$\begin{array}{l}20 \text { mil até menos } \\
\text { de } 50 \mathrm{mil}\end{array}$} & \multicolumn{2}{|c|}{$\begin{array}{l}50 \text { mil até menos } \\
\text { de } 100 \text { mil }\end{array}$} & \multicolumn{2}{|c|}{$\begin{array}{c}\text { Acima de } \\
100 \mathrm{mil}\end{array}$} & \multicolumn{2}{|c|}{ Total } \\
\hline & $\mathbf{N}$ & $\%$ & $\mathbf{N}$ & $\%$ & $\mathbf{N}$ & $\%$ & $\mathrm{~N}$ & $\%$ & $\mathbf{N}$ & $\%$ & $\mathbf{N}$ & $\%$ \\
\hline Autônomo & 80 & 0,77 & 1.058 & 10,24 & 1.216 & 11,77 & 431 & 4,17 & 5.065 & 49,03 & 7.850 & 75,99 \\
\hline Bolsa & 3 & 0,03 & 11 & 0,11 & 15 & 0,15 & 2 & 0,02 & 9 & 0,09 & 40 & 0,39 \\
\hline Cargo comissionado & 54 & 0,52 & 119 & 1,15 & 61 & 0,59 & 10 & 0,10 & 23 & 0,22 & 267 & 2,58 \\
\hline Consultoria & 2 & 0,02 & 2 & 0,02 & 6 & 0,06 & 1 & 0,01 & 2 & 0,02 & 13 & 0,13 \\
\hline $\begin{array}{l}\text { Contrato por prazo } \\
\text { determinado }\end{array}$ & 147 & 1,42 & 732 & 7,09 & 347 & 3,36 & 232 & 2,25 & 487 & 4,71 & 1.945 & 18,83 \\
\hline Contrato verbal/informal & 13 & 0,13 & 34 & 0,33 & 10 & 0,10 & 3 & 0,03 & 31 & 0,30 & 91 & 0,88 \\
\hline Cooperativa & - & - & 6 & 0,06 & 7 & 0,07 & 1 & 0,01 & 12 & 0,12 & 26 & 0,25 \\
\hline Estágio & 4 & 0,04 & 16 & 0,15 & 4 & 0,04 & 6 & 0,06 & 15 & 0,15 & 45 & 0,44 \\
\hline Residência & - & - & - & - & - & - & - & - & 53 & 0,51 & 53 & 0,51 \\
\hline Total & 303 & 2,93 & 1.978 & 19,15 & 1.666 & 16,13 & 686 & 6,64 & 5.697 & 55,15 & 10.330 & 100 \\
\hline
\end{tabular}

Fonte: BRASIL, 2014 
Comparando-se os vínculos considerados precários $(\mathrm{N}=10.330)$ com o total de vínculos de trabalho na região estudada $(\mathrm{N}=28.329)$, observou-se que os municípios com população entre 50 mil e 100 mil habitantes possuem, no total, 2.516 vínculos de trabalho no setor saúde, dos quais $27,27 \%$ são precários. Em contrapartida, os municípios com população entre 20 mil e 50 mil habitantes possuem 4.121 vínculos de trabalho, dos quais $40,43 \%$ estão em situação de precariedade. As demais categorias de porte dos municípios apresentam percentuais de precarização entre $28 \%$ e $39 \%$.

Ao analisar a situação de precarização dos vínculos de trabalho em cada um dos municípios da região estudada, observou-se que tanto o município com percentual mais elevado de vínculos precários - Itaipulândia (PR), com $77 \%$ dos vínculos considerados precários - quanto o município com menor percentual de vínculos precários - Braganey (PR), com 5,13\% - são municípios com porte populacional entre 5 mil e 20 mil habitantes. Desta forma, existe a necessidade de que outros estudos ampliem a compreensão acerca da relação entre o porte populacional e a precarização de vínculos de trabalho nas redes municipais de saúde.

Diversos autores (ANDRADE, 2009; PINTO; TEIXEIRA, 2011) têm apontado que a gestão do trabalho em saúde se constitui como um nó crítico para a consolidação do SUS e para a garantia do direito à saúde. As diversas modalidades precárias de vinculação ao trabalho evidenciadas no presente estudo apontam que um contingente significativo de trabalhadores da saúde na macrorregião oeste do Paraná está sujeito a vivenciar um processo denominado por Minayo Gomez e Thedim-Costa (1999) como de pauperização e degradação das condições materiais de vida, resultado da tendência de perpetuação da precarização e do desemprego, agravado pela ausência de mecanismos de proteção social e pela impossibilidade apresentada pela lógica da livre regra do mercado de reabsorver a população excluída e à margem de qualquer sistema previdenciário.

\section{Conclusões}

A situação da precarização dos vínculos trabalhistas na macrorregião oeste do Paraná apresenta-se diversificada. Os profissionais de nível superior que desempenham atividades nucleares são os mais atingidos e, dentre estes, os médicos apresentam a situação mais preocupante. Os trabalhadores da enfermagem apresentam, em sua maioria, vínculos relativamente protegidos.

Quanto ao porte populacional dos municípios, foram identificados municípios de portes semelhantes com percentuais altos de precarização dos vínculos e outros com percentuais inferiores. Os vínculos precários ocorrem, predominantemente, nos serviços privados ou municipais e na atenção hospitalar ou intermediária.

Salienta-se a necessidade da realização de estudos, especialmente de abordagens qualitativas, que analisem a precarização do trabalho nas suas outras dimensões (condições, organização e ambiente de trabalho, representatividade dos trabalhadores, repercussões na saúde do trabalhador etc.), além dos próprios vínculos de trabalho. 


\section{Referências}

AGUIAR FILHO, W. A gestão do trabalho em saúde no MERCOSUL. 2012. 128f. Dissertação (Mestrado Profissional em Saúde Pública) - Escola Nacional de Saúde Pública Sergio Arouca, Fundação Oswaldo Cruz, Rio de Janeiro, 2012.

ANDERSON, P. Balanço do neoliberalismo. In: SADER, E.; GENTILI, P. (Org.). Pós-neoliberalismo: as políticas sociais e o Estado democrático. 6. ed. Rio de Janeiro: Paz e Terra, 2003.

ANDRADE, L. R. de. A FE no SUS: Fundação Estatal como proposta de gestão do trabalho para a Estratégia Saúde da Família na Bahia. 2009. 130f. Dissertação (Mestrado Profissional em Saúde Pública) - Escola Nacional de Saúde Pública Sergio Arouca, Fundação Oswaldo Cruz, Rio de Janeiro, 2009.

ANTUNES, R. Adeus ao trabalho? Ensaio sobre a metamorfose e a centralidade do mundo do trabalho. 3. ed. São Paulo: Cortez, 1995.

BORSOI, I. C. F. Vivendo para trabalhar: do trabalho degradado ao trabalho precarizado. Convergência, Revista de Ciencias Sociales, Universidad Autónoma del Estado de México (UAEM), n. 55, enero./abr. 2011.

BRASIL. Conselho Nacional de Secretários de Saúde. Gestão do trabalho e da educação na saúde. Brasília, 2011.

Ministério da Saúde. Gestão do trabalho e da regulação profissional em saúde: agenda positiva do Departamento de Gestão e da Regulação do Trabalho em Saúde. 3. ed. Brasília, 2009.

Ministério da Saúde. Programa Nacional de Desprecarização do Trabalho no SUS (DesprecarizaSUS): perguntas \& respostas. Brasília, 2006a.

Ministério da Saúde. Secretaria de Atenção à Saúde. Cadastro Nacional de Estabelecimentos de Saúde [internet]. Disponível em:<http://cnes.datasus.gov.br/>. Acesso em: 13 mar. 2014

Ministério da Saúde. Secretaria de Atenção à Saúde. Manual do Cadastro Nacional dos Estabelecimentos de Saúde, Versão 2. Brasília, 2006b.

CARVALHO, C. L.; GIRARDI, S. N. (Coord.). Agentes institucionais e modalidades de contratação de pessoal no Programa Saúde da Família no Brasil. Relatório de pesquisa. Belo Horizonte, fev. 2002. 90p.

DEDECCA, C. S. O trabalho no setor saúde. São Paulo em perspectiva, São Paulo, v. 22, n. 2, p. 87-103, jul./dez. 2008.

DEDECCA, C. S. et al. A dimensão ocupacional do setor de atendimento à saúde no Brasil. Trabalho, Educação e Saúde, Rio de Janeiro, v. 3, n. 1, p. 123-142, 2005.

DEDECCA, C. S; TROVÃO, C. J. B. M. A força de trabalho no complexo da saúde: vantagens e desafios. Ciência \&t Saúde Coletiva, Rio de Janeiro, v. 18, n. 6, p. 1555-1567, jun. 2013.

FARIA, H. X.; DALBELLO-ARAUJO, M. Precarização do trabalho e processo produtivo do cuidado. Mediações, Londrina, v. 16, n. 1, p. 142-156, jan./jun. 2011.

GARCIA, A. C. P. Gestão do trabalho e da educação na saúde: uma reconstrução histórica e política. 2010. 171f. Tese (Doutorado em Saúde Coletiva) - Instituto de Medicina Social, Universidade do Estado do Rio de Janeiro, Rio de Janeiro, 2010.

KALLEBERG, A. L. O crescimento do trabalho precário: um desafio global. Rev. Bras. Ci. Soc., São Paulo, v. 24, n. 69, fev.2009.

KOSTER, I. A Gestão do Trabalho e o contexto da flexibilização no Sistema Único de Saúde. 2008. 208f. Dissertação (Mestrado em Saúde Pública) - Escola Nacional de Saúde Pública Sergio Arouca, Fundação Oswaldo Cruz, Rio de Janeiro, 2008.

MINAYO-GOMEZ, C.; THEDIM-COSTA, S. M. F. Precarização do trabalho e desproteção social: desafios para a saúde coletiva. Ciência \&t Saúde Coletiva, Rio de Janeiro, v. 2, n. 4, p. 411-421, 1999.

MONTAÑO, C.; DURIGUETTO, M. L. Estado, classe e movimento social. 3. ed. São Paulo: Cortez, 2011.

NOGUEIRA, R. P. Problemas de gestão e regulação do trabalho no SUS. Serviço Social e Sociedade, São Paulo, v. 87, p. 147-62, 2006.

PARANÁ. Secretaria Estadual de Saúde (SESA). Plano Diretor de Regionalização: hierarquização e regionalização 
da assistência à saúde no Estado do Paraná, 2009.

Disponível em: $<$ http://www.sesa.pr.gov.br/arquivos/File/

PDR_atualizado_Edson.pdf>. Acesso em: 23 jul. 2012.

PAULO NETTO, J. Crise do socialismo e ofensiva neoliberal. São Paulo: Cortez, 1993.

PINTO, I. C. M.; TEIXEIRA, C. F. Formulação da política de gestão do trabalho e educação na saúde: o caso da Secretaria Estadual de Saúde da Bahia, Brasil, 2007-2008. Cad. Saúde Pública, Rio de Janeiro, v. 27, n. 9, set. 2011.

SILVA, E. V. M.; SILVA, S. F. O desafio da gestão municipal em relação à contratação da força de trabalho em saúde. Divulgação em Saúde para Debate, Rio de Janeiro, n. 40, p. 7-12, jun. 2007.
SILVEIRA, D. S. et al. Gestão do trabalho, da educação, da informação e comunicação na atenção básica à saúde de municípios das regiões Sul e Nordeste do Brasil. Cad. Saúde Pública, Rio de Janeiro, v. 26, n. 9, Rio de Janeiro, p. 1714-1726, set. 2010.

Recebido para publicação em setembro de 2014

Versão final em dezembro de 2014

Conflito de interesse: inexistente

Suporte financeiro: Fundação Araucária- Chamada Pública 04/2012 - Programa de pesquisa para o Sistema Único de Saúde: Gestão compartilhada em saúde PPSUS - Edição 2011. Processo $n=35038$ 